\title{
Raíces. El olivo en la lucha identitaria entre Israel y Palestina
}

\section{Roots. The olive tree in the identity struggle between Israel and Palestine}

\author{
Julieta Espín Ocampo \\ Facultad de Ciencias Sociales y de la Comunicación; \\ Universidad Europea (Madrid, España) \\ julieta.espin@universidadeuropea.es
}

\begin{abstract}
Resumen
La lucha por el territorio palestino se desarrolla no sólo en la arena militar y política, sino que se amplía a la económica y cultural. En el imaginario tanto israelí como palestino, el árbol del olivo se ha convertido en un símbolo de la identidad palestina y su resistencia a la ocupación. Esta disertación pretende analizar cómo a partir de 1967 el nacionalismo palestino ha sido moldeado por la ocupación israelí de la franja de Gaza, Cisjordania y Jerusalén Oriental, desarrollando diferentes formas de resistencia. En particular, se centra en describir cómo los campos de olivos de Cisjordania se han convertido en alegorías de la resistencia palestina a la dominación militar, económica y cultural israelí. Además de su incidencia en la precaria economía de los Territorios Ocupados, la carga simbólica de este árbol lo ha convertido en un nuevo instrumento de batalla entre los habitantes palestinos, las Fuerzas de Defensa de Israel (FDI) y los colonos de los asentamientos.
\end{abstract}

\section{Palabras Clave}

Palestina; Israel; identidades; olivo; colonos.

\begin{abstract}
The struggle for the Palestinian territory unfolds not only the military and political arena, but also expands to economic and cultural ones. In both Israeli and Palestinian public imagination, the olive tree has become a symbol of Palestinian identity and its resistance to military occupation. This work aims to analyze how since 1967 Palestinian nationalism has been shaped by the Israeli occupation of Gaza Strip, the West Bank and East Jerusalem, developing different forms of resistance. Notably, it focuses on describing how West Bank's olive groves have become allegories of Palestinian resistance to Israeli military, economic and cultural domination. In addition to its impact on the precarious economy of the




\section{Julieta Espín Ocampo}

occupied Palestinian territories, the symbolic weight of this tree has turned it into a tool in the battle between Palestinian inhabitants, the Israel Defense Forces (IDF) and the Israeli settlers.

\section{Keywords}

Palestine; Israel; identities; olive; settlers.

\section{Introducción}

Aunque el nacionalismo palestino encuentra sus raíces en el siglo XIX, el colonialismo sionista dejará su impronta en el desarrollo de la identidad nacional palestina consolidada en el siglo XX. Dos hechos históricos serán esenciales para entender la construcción de dicha identidad: la Nakbah (El desastre), es decir, la desposesión palestina tras la creación del Estado de Israel en 1948, que convertiría a más del 70\% de la población en refugiada; y la Naksa (la nueva derrota o recaída) de 1967, cuando Israel ocupa el resto de la Palestina histórica (Jerusalén Oriental, la Franja de Gaza y Cisjordania) y somete a sus pobladores a un régimen que ejerce abusos, violencia y desposesión territorial e identitaria. Mientras el liderazgo palestino en el exterior se decantaba por la lucha armada contra Israel, los palestinos bajo ocupación militar optaron principalmente por una resistencia de carácter no violento. Resistencia ante las Fuerzas de Defensa de Israel (FDI), pero también ante la violencia y agresividad de los colonos israelíes.

El presente artículo indaga sobre el entorno político y social en el que discurren las relaciones desiguales entre los palestinos de los Territorios Ocupados e Israel. Este marco nos introduce en la identidad nacional bajo la ocupación, incidiendo en las asimetrías de las narrativas israelí/sionista y palestina, para poder abordar algunos elementos claves de la identidad palestina. Posteriormente, se describe cómo los olivos y los olivares se han incluidos en esta lucha por el territorio.

Resulta necesario apuntar que existen pocos artículos académicos que aborden la cuestión del olivo en la lucha identitaria de los Territorios Ocupados, por lo que una importante parte de las fuentes utilizadas en la elaboración de esta investigación descriptiva, han sido informes y notas de prensa presentados por organizaciones no gubernamentales israelíes, palestinas e internacionales que velan por los derechos humanos de en dichos territorios, de la Agencia de Naciones Unidas para los Refugiados de Palestina en Oriente Próximo (UNRWA) y la Oficina de Coordinación de Asuntos Humanitarios de las Naciones Unidas (OCAH), así como de algunos artículos periodísticos. Los datos sobre el sector agrícola en Gaza y Cisjordania son cifras ofrecidas por Naciones Unidas y algunas de sus agencias, como la Organización de Naciones Unidas para la Alimentación y la Agricultura (FAO) y la Conferencia de las Naciones Unidas sobre Comercio y Desarrollo (UNCTAD). Ello a falta de información oficial actualizada por parte de la Autoridad Palestina. 


\section{Raíces. El olivo en la lucha identitaria entre Israel y Palestina}

\section{Las narrativas en la construcción de la identidad}

Tal como indica Isaías Barreñada (2003: 276), en los conflictos coloniales las identidades del colono o del colonizado se sitúan en el centro de la disputa política. La memoria colectiva se convierte en constructora de identidad, encuadrada en marcos sociales y relaciones de poder. En ella los códigos culturales aseguran la identidad del grupo, que implica un proceso de transmisión y recepción de tópicos por los que el pasado es evocado en función de las ambiciones y objetivos del presente (Rovira, Dell'Aquila y Seminara, 2016: 4). Considerando el sionismo una empresa colonial, éste ha logrado articular una narrativa nacional generada desde el propio Estado israelí que unifica a la población judeo-israelí y que legitima la dominación y expansión del control territorial de la Palestina histórica. Como cualquier otro Estado, Israel cuenta con los medios (educativos, sociales, de comunicación, académicos, etc.) para construir e implantar dicha narrativa entre sus ciudadanos y, en cierta medida, exportarla fuera del país. Por un lado, intenta justificar los derechos históricos del pueblo judío sobre Palestina basados en textos religiosos; por otro lado, evita cualquier especificidad de la población autóctona respecto a otras comunidades o regiones vecinas, considerando a los pobladores simplemente como "árabes", negándoles así cualquier vinculación con la tierra y una identidad diferenciada (Barreñada, 2003: 276), lo que anularía cualquier demanda territorial o política de los palestinos. Desde 1948, esta estrategia se materializa, entre otras formas, en la erradicación de los nombres árabes de las poblaciones y regiones bajo soberanía o control militar israelí, sustituyéndolos por nombres en hebreo y/o con connotaciones bíblicas. Esta política genera nuevas identidades geográficas israelíes que ocultan las palestinas y así, niegan su existencia. De esta manera, a partir de 1967, Cisjordania pasó a designarse como Judea y Samaria en el lenguaje oficial israelí, y los palestinos que viven en ella son considerados "refugiados árabes" o "árabes de los territorios" (Martinelli, 2016: 25).

Por su parte, la ausencia de una entidad estatal propia ha dificultado (aunque no impedido), la gestación de un discurso y narrativa palestina homogénea que cale con el mismo éxito de su contraparte israelí. Así pues, al dividirse la población entre refugiados y residentes en los Territorios Ocupados (sin contar con los árabes de Israel), la identidad nacional ${ }^{1}$ y la defensa de esta, se han construido desde dos diferentes frentes y con distintas herramientas. Por un lado, entre los refugiados palestinos a través de la reagrupación en los campamentos según los lugares de origen, la idealización de la tierra arrebatada, la resistencia a la asimilación en los países de acogida, la exigencia del derecho al retorno y la lucha armada. Por otro lado, entre los palestinos de los Territorios Ocupados, a través de la resiliencia ante

\footnotetext{
${ }^{1}$ La identidad nacional es descrita por Talavera (1999) como "[...] el sentimiento subjetivo del individuo a pertenecer a una nación concreta, a una comunidad en la que existen diversos elementos que la cohesionan y la hacen única, como por ejemplo la lengua, la religión, la cultura, la etnia, etc.; siendo estos elementos objetivos sobre los cuales se asienta el sentimiento de pertenencia a una comunidad, una comunidad nacional".
} 
los abusos de la potencia ocupante ${ }^{2}$ y la violencia de los colonos, materializada en la resistencia no violenta o sumud (firmeza o resiliencia).

A pesar de esta diferenciación en orígenes y evolución del nacionalismo palestino, existen elementos que unifican la filiación palestina dentro y fuera de los Territorios Ocupados. Así pues, según Rosemary Sayigh (1977: 21), el desarrollo de la identidad palestina se ha basado en: a) una historia que diverge profundamente de la de otros pueblos árabes; b) una situación de destitución, dispersión, pobreza, opresión y control ejercido por no palestinos; c) la ambigüedad en el apoyo árabe, discrepancia entre el apoyo verbal "a la causa" y el tratamiento dado a los palestinos; d) el desarrollo de otras identidades sub-árabes (jordana, siria, etc.), alrededor de los regímenes e intereses regionales; e) el establecimiento de la OLP y el surgimiento del movimiento de resistencia; y f) factores indígenas tales como la solidaridad familiar y los lazos vecinales entre los palestinos de origen rural, su experiencia histórica de autodependencia y de supervivencia.

\section{La ocupación de 1967: expropiación y colonización}

La ocupación total de la Palestina histórica por parte de Israel desde 1967 supuso una vuelta de tuerca más en la lucha palestina que se adaptó a las nuevas circunstancias. A diferencia de 1948, Israel no pretendió la anexión inmediata de los nuevos territorios de Gaza y Cisjordania, por las consecuencias demográficas que podría acarrear en el carácter judío del Estado. Otorgar la ciudadanía y voto a una población árabe que crecía más que la judía era impensable. La estrategia emprendida desde entonces será la de anexión escalonada de territorio palestino a través de confiscación de tierras, expulsión de los pobladores y la construcción de asentamientos judíos a lo largo y ancho de los Territorios, pero en especial Cisjordania y en Jerusalén Oriental (proclamada unilateralmente capital israelí desde 1980) ${ }^{3}$. Se calcula que desde 1969 se han emitido más de 1.150 órdenes de confiscación de propiedades en Cisjordania (Hass, 2019), basadas en un conjunto de leyes, llamadas de los ausentes, que permite a Israel hacerse de tierras palestinas si se documenta que la tierra ha estado abandonada por tres años (Hammad, 2019). Asimismo, el argumento de la seguridad también ha sido utilizado recurrentemente para la anexión israelí de nuevos territorios. Así pues, Israel ha buscado la

\footnotetext{
${ }^{2}$ Israel es firmante de la Cuarta Convención de Ginebra de 1949, que en su Sección Tercera establece las obligaciones de las potencias ocupantes y provisiones para proteger a los civiles en los territorios bajo ocupación, entre ellas, la prohibición de construir en tierras ocupadas.

${ }^{3}$ Jerusalén Esta estuvo bajo administración jordana desde 1948 hasta 1967 cuando fue ocupada por los israelíes. En julio de 1980, el parlamento israelí aprueba la ley básica que establece a Jerusalén como la capital "eterna e indivisible" de Israel. De esta forma, se daba carácter legal a la unificación de la ciudad que de facto estado hebreo había realizado tras la ocupación de Jerusalén Este, incluyendo la Ciudad Vieja, desde 1967. El Consejo de Seguridad de la ONU aprobaría la resolución 478, que rechazaría dicha ley, considerándola contraria al derecho internacional.
} 


\section{Raíces. El olivo en la lucha identitaria entre Israel y Palestina}

emigración forzada o inducida de la población local, su expulsión y la apropiación de sus territorios (Abu Quevedo, 2002: 160).

Respecto a la construcción de asentamientos de colonos de israelíes ésta comenzó prácticamente desde el inicio de la ocupación en $1967^{4}$, buena parte de ellos creados en zonas confiscadas por Israel para convertirlas en "zona militar cerrada", sin acceso para la población palestina. Judíos nacidos en Israel y el extranjero ${ }^{5}$ encontraron diferentes incentivos para mudarse a los asentamientos. Los más secularizados por incentivos de tipo económico como ventajas fiscales, subvenciones y préstamos a bajo interés; los ultranacionalistas y fundamentalistas por motivaciones religiosas impulsadas por los partidos israelíes ultrareligiosos y por el partido Likud (Abu Quevedo, 2002: 159).

De acuerdo al Centro de Información Israelí por los Derechos Humanos en los Territorios Ocupados B'TSELEM (2017a), de 1967 a finales de 2017, existían más de 200 asentamientos israelíes en Cisjordania ${ }^{6}$, de los cuales 131 estaban reconocidos oficialmente por el Ministerio del Interior Israelí. En todos ellos residen más de 620.000 colonos, de los cuales unos 209.270 viven en los terrenos que Israel anexó a la municipalidad de Jerusalén. Los asentamientos han sido el instrumento utilizado para establecer una táctica política de hechos consumados en la política territorial israelí, porque no sólo se confisca el territorio donde se encuentran los asentamientos, sino aquel necesario para establecer una red de carreteras para su uso exclusivo, barricadas, checkpoints, etc., que limitan el libre movimiento de los palestinos y que en ocasiones niegan el acceso de los propietarios a sus tierras de cultivo. En este sentido, es destacable la creación del Muro de Separación que aprobó construir Israel en 2002, que discurre unos 800 kilómetros a lo largo de toda Cisjordania y rodea Jerusalén. Su construcción se justificaba por dos objetivos: para separar los asentamientos judíos y las poblaciones israelíes de los pueblos y villas palestinos, y para evitar el ingreso de posibles terroristas a territorio israelí. El muro, trazado en partes en hormigón y en otras con una valla electrificada, se ha construido en un $80 \%$ sobre tierras palestinas ${ }^{7}$, aislando tanto poblaciones como áreas de cultivo.

\footnotetext{
${ }^{4}$ En la guerra de 1967 también se ocupó el Sinaí egipcio y los Altos del Golán sirios, éstos aún bajo control israelí y con más de 30 asentamientos judíos. Las colonias judías establecidas en la península del Sinaí fueron desmanteladas tras los acuerdos de paz entre Egipto e Israel de 1979.

${ }^{5}$ En 1950, el Parlamento israelí promulgó la Ley del Retorno, que concede la residencia a todos los judíos o descendientes de judíos hasta la tercera generación de cualquier lugar del mundo que deseen emigrar Israel. Dos años después, la Ley de Ciudadanía otorgaba a todos estos inmigrantes la nacionalidad israelí. En 1970 se amplió el derecho a obtener la ciudadanía israelí "también al hijo y al nieto de un judío, a la pareja de un judío, y a la pareja del hijo y nieto de un judío, exceptuando a quien era judío y cambió de religión por voluntad propia."

${ }^{6}$ Otros 16 que se habían creado en la Franja de Gaza y 4 en el norte de Cisjordania fueron desmantelados en 2005, como parte del Plan de Desconexión. Aunque ya no existen asentamientos en la Franja, Israel perpetúa su control aéreo, marítimo y terrestre sobre dicho espacio, que en la actualidad se encuentra sujeto a un bloqueo.

${ }^{7}$ El muro ha creado una nueva frontera de facto que supondría la anexión israelí de un 8,5\% del territorio cisjordano.
} 
Los Acuerdos de Oslo de 1993 entre la Organización para la Liberación de Palestina (OLP) e Israel, no trajeron cambios significativos ni en el proceso de anexión territorial ni en la construcción de nuevos asentamientos. Hasta cierto punto, incluso ha incrementado ambos procesos, dado que Israel aún controla el 62,9\% del territorio cisjordano ${ }^{8}$, es decir la llamada Área C de dichos Acuerdos, aprovechados por Israel para extender su barrera de separación y construir nuevos asentamientos, conforme a su política de hechos consumados. Tal como indica Marcelo Otero (2017: 58), la creación de limitaciones cotidianas al movimiento de los campesinos palestinos parece ser una preparación para el desalojo definitivo, la construcción de una normalidad de permanente crisis para las comunidades de los Territorios Ocupados.

\section{Sumud: la resistencia no violenta}

A diferencia de 1948, cuando el 70\% de la población palestina huyó para salvar la vida y terminó convirtiéndose en la comunidad de refugiados más antigua de la historia moderna, en 1967 la inmensa mayoría de los palestinos, durante y después de la guerra, permaneció en sus hogares. La ocupación transformó profundamente la estructura socioeconómica de los Territorios, a través del paulatino incremento del desempleo y las restricciones al comercio debido al recurrente cierre de carreteras y accesos a Israel, la ausencia de estabilidad o seguridad jurídica y física necesarias para invertir, la disminución de las propiedades y tierras para la producción debido a las expropiaciones (Abu Quevedo, 2002: 167). Al mismo tiempo, la ocupación introdujo una transformación demográfica con la creación de los asentamientos israelíes.

Tras la victoria israelí de 1967, los primeros empeños palestinos de reacción armada contra la ocupación tuvieron un elevado coste en términos de vidas humanas, castigos colectivos, encarcelamientos y deportaciones debido al poder asimétrico de los bandos. Como consecuencia, la resistencia armada dentro de los Territorios quedó muy debilitada debido a la presencia de las FDI. Hasta la primera intifada ${ }^{9}$ de 1987, el liderazgo de la resistencia armada y política se encontraría en la periferia

\footnotetext{
${ }^{8}$ En 1995, el Acuerdo de Taba u Oslo II dividiría Cisjordania en 3 diferentes áreas: A, B y C que se irían modificando conforme el avance de las negociaciones Actualmente y tras años de estancamiento en las negociaciones, en Cisjordania el Área A con el 53\% de la población y el 18,3\% del territorio está bajo control civil y de seguridad palestino; el Área B, con el $41 \%$ de la población y el 18,8\% del territorio, el control civil lo tiene la Autoridad Palestina, y la seguridad queda compartida con los israelíes; y finalmente el Área C, con el 5,8\% de la población y el 62,9\% del territorio queda bajo control total israelí en términos de seguridad y planificación y es el espacio de los pueblos agrarios. La franja de Gaza no se regía por esta división.

${ }^{9}$ La primera intifada fue el levantamiento popular y masivo palestino en contra de la ocupación israelí en Gaza y Cisjordania entre 1987 y 1993. Las imágenes de jóvenes y niños palestinos luchando con piedras contra tanques y soldados fuertemente armados desprestigiarían la imagen de Israel y serían uno de los factores desencadenantes de las iniciativas de paz de 1991 en Madrid y 1993 en Oslo. En el contexto de este levantamiento popular también surgiría un nuevo actor en la sociedad palestina, el Movimiento de Resistencia Islámica, Hamás.
} 


\section{Raíces. El olivo en la lucha identitaria entre Israel y Palestina}

de la Palestina histórica, principalmente en Jordania, en Líbano y en Túnez. ${ }^{10}$ Sería entonces otro tipo de resistencia de carácter civil y no violenta, obligada a lidiar diariamente con la ocupación, la que terminaría por prevalecer en los Territorios. Tal como indica Abu Quevedo, "la pauta generalizada de los habitantes de Gaza y Cisjordania fue de recogimiento al ámbito privado ante la decepción que causaron la derrota árabe, el fracaso de la estrategia guerrillera, la represión israelí, y las apremiantes necesidades materiales de subsistencia" (Abu Quevedo, 2002: 159).

El concepto de sumud que se traduciría como firmeza o resiliencia, es un elemento destacable de la resistencia palestina a la ocupación militar y a los intentos de expulsión de su patria, y por tanto, de la narrativa identitaria entre los palestinos que remarca el sentimiento de apego y anclaje a la propia tierra. Supone "una firme determinación de permanecer, de luchar, de lucha militante y de resistencia no violenta" (Martinelli, 2016: 31), que reivindica que existir, es decir, el estar ahí, es resistir (Rijke y Teenffelen, 2014). Resistencia basada no en el heroísmo sino en la supervivencia diaria (Martinelli, 2016: 32). El sumud se manifestó tanto de manera organizada como de forma espontánea e individual. La primera a través de la construcción de instituciones nacionales como municipios, centros de estudio e investigación, publicaciones y asociaciones de beneficencia y socioculturales, movimientos estudiantiles, etc. (Abu Quevedo, 2002: 217). La segunda, más popular, a través del uso cotidiano de símbolos tradicionales como la kufiya, el pañuelo blanco y negro que usaban los campesinos y beduinos palestinos, en la danza, en el teatro, la poesía, etc. (Martinelli, 2016: 32), pero también en el cultivo de la tierra.

\section{El sector agrícola bajo la ocupación}

Desde los albores del nacionalismo palestino, la economía regional ya era eminentemente agrícola, y para 1967, la economía de Cisjordania seguía dependiendo mayoritariamente del sector primario. Pero a partir de entonces, el sector agrícola padeció enormemente los efectos de la ocupación debido a las restricciones al movimiento, la expropiación de tierras y aguas, la falta de ayudas gubernamentales al campo, y la competencia desleal de los productos agrícolas israelíes (Abu Quevedo, 2002: 245). Los Acuerdos de Oslo no mejorarían sustancialmente la libertad de movimiento en Cisjordania, lo que agravaría su producción agrícola: según la Organización de Naciones Unidas para la Alimentación y la Agricultura (FAO, 2017: 22), la combinación de las restricciones impuestas en

\footnotetext{
10 En 1967 George Habash, médico palestino refugiado en Jordania, fundaría el Frente Popular para la Liberación de Palestina (FPLP), de corte marxista, desde donde lanzaría ataques no sólo contra Israel sino contra el propio gobierno jordano. Abu Nidal, también en Jordania y tras escindirse de Fatah, fundaría otro grupo guerrillero, El Consejo Revolucionario, conocido también como Organización Abu Nidal (OAN). Al Fatah o Movimiento Nacional para la Liberación de Palestina, principal organización dentro de la OLP, fue creada por Yasser Arafat en 1959 y a lo largo de su historia, sus brigadas lanzaron ataques sobre territorio israelí sobre todo desde territorio jordano y libanés, hasta su expulsión a Túnez en 1983.
} 
las zonas B y C (como el régimen de permisos para transitar por la zona $\mathrm{C}$ y los cierres de carreteras y accesos) y el muro de separación, han dejado al 50\% de la tierra cultivable cisjordana inaccesible a sus dueños árabes (FAO, 2017: 22).

Así pues, las restricciones al movimiento a través de instalaciones militares y checkpoints, por ejemplo, ha supuesto un aumento del coste de los productos palestinos de un 35,6\% desde 2000; además, los tiempos necesarios para el transporte han aumentado cerca de un 40\%. Asimismo, Israel ha confiscado o destruido muchas de las fuentes de agua: si en 1967 había 774 pozos en Cisjordania, en 2005 sólo quedaban 328 pozos en funcionamiento (Llopis). De toda tierra cultivable de Gaza y Cisjordania, sólo el 19\% se irriga (FAO, 2017: 22). De hecho, Israel ha estado extrayendo mucha más agua del nivel estipulado por los acuerdos de Oslo y ha confiscado en $82 \%$ de las aguas subterráneas, por lo que los palestinos han debido "importar" su propia agua de Israel (UN News, 2016). Mientras la población israelí casi duplica a la palestina, su consumo de agua es 7,5 veces más alto, y hasta 9 veces en el caso de los asentamientos (Otero, 2017: 59)

Respecto a los cultivos principales, históricamente en Gaza solía predominar la horticultura, sobre todo los cítricos, pero debido a las crecientes dificultades de acceso a la tierra y el agua, éstos están siendo sustituidos por olivos y palmas, más resistentes a la falta de agua y menos necesitadas de cuidados. Se produce y exporta además de los ya mencionados, verduras, almendros, uvas y flores. Resulta alarmante el dato referente a la drástica reducción del peso de la agricultura en el PIB palestino. En el caso de Cisjordania ha pasado del 14\% a mediados de los noventa, a apenas un 4,5\% en 2014 (FAO, 2017: 22), por lo que actualmente la producción interna no cubre la propia demanda, y los palestinos dependen de los excedentes importados desde Israel para cubrir sus necesidades mínimas.

\section{El olivo}

Por milenios, diferentes civilizaciones han considerado al olivo como un árbol robusto, que relativamente requiere pocos cuidados, pero mucho tiempo para dar sus frutos. La Grecia y Roma clásicas estaban impregnadas de historias y mitos relativos al olivo que terminaron por convertirlo en símbolo de fecundad y victoria. La tradición judeo-cristiana, gracias a la historia de Noé, añadiría a este árbol su representación de paz y esperanza, símbolo utilizado en noviembre de 1974 por el representante de la OLP, Yasser Arafat, en su histórico discurso ante la Asamblea de Naciones Unidas. ${ }^{11}$

Según datos de la Conferencia de las Naciones Unidas sobre Comercio y Desarrollo (UNCTAD), desde 1967, aproximadamente 2,5 millones de árboles frutales, de ellos

\footnotetext{
11 "Hoy he venido portando una rama de olivo en una mano y el arma de un luchador por la libertad en la otra. No dejen que caiga de mi mano el ramo de olivo. Repito: no dejen que caiga de mi mano la rama de olivo". Discurso completo disponible en https://www.marxists.org/espanol/arafat/1974/onu-13nov.htm
} 


\section{Raíces. El olivo en la lucha identitaria entre Israel y Palestina}

unos 800.000 olivos, has sido arrancados o destruidos por la FDI, o por los colonos de los asentamientos en Cisjordania (UN News, 2016). Dicha destrucción tiene implicaciones económicas, políticas, legales e identitarias.

En términos económicos, la producción de aceitunas y aceite de oliva ha sido central para el sector agrícola palestino. Se calcula que cada olivo romano -la variedad común en Palestina- produce anualmente aceite por valor de 150 a 280 dólares (Hammad, 2019). Aproximadamente el $45 \%$ de la tierra arable de Gaza y Cisjordania está plantada con 12 millones de olivos, y en Cisjordania, la industria aceitunera representa aproximadamente el 25\% del valor total de la producción agrícola, algo más de 100 millones de dólares en ingresos (Oxfam, 2010) lo que supone que unas 10.000 familias dependen de ella (United Nations Office for the Coordination of Humanitarian Affairs, 2011). El 90\% de la producción se destina a la producción de aceite, procesado en unos de las 194 almazaras de los Territorios (Braverman, 2009). La destrucción de los olivos se enmarca en un proceso continuo de abandono de campo que deforma la estructura de la economía palestina (UN News 2016). En términos legales, la destrucción de los olivares es el primer paso para confiscar a sus dueños árabes la tierra en la que se asientan. Conforme a las leyes israelíes mencionadas anteriormente, Israel puede expropiar aquellas propiedades "abandonadas" por sus legítimos dueños después de tres años de ausencia ${ }^{12}$. En este sentido, los olivos dan protección legal a la tierra, por lo que no puede ser expropiada por Israel u ocupada legalmente por colonos israelíes. Al destruirlos, se elimina dicha protección jurídica. Para 2019, se calculaba que había unos 3.200 casos contra la confiscación de tierras y propiedades en los juzgados israelíes (Hammad, 2019). Otra razón aducida para arrancar los árboles han sido la seguridad, dado que, según las FDI, los olivares han sido utilizados como escondite para atacar o emboscar a los colonos o a los propios militares israelíes (Lynfield, 2000). No obstante, los palestinos consideran la destrucción de sus huertos como un acto de castigo colectivo, sobre todo porque estas acciones se intensificaron a partir del 2000, con el inicio de la segunda Intifada. Tal como interpreta el proyecto de Monitorización de las Actividades de Colonización Israelíes, Tel Aviv ha elegido "hacer la guerra contra el pueblo palestino no sólo en el campo de batalla, sino también en los campos de olivos" (Sarafa, 2004). De hecho, la construcción del famoso Muro de Separación supuso el arrancar decenas de miles de olivos a lo largo de sus 800 kilómetros, y sólo la presión internacional hizo que Israel asegurara que trasplantaría todos esos árboles donde los dueños lo indicaran, sin tomar en cuenta que muchos propietarios no tienen terrenos alternativos para ello (Braverman, 2009: 248-249).

Finalmente, en términos políticos y sociológicos, la lucha por la destrucción o supervivencia de los olivos se enmarca en la narrativa de la construcción nacional israelí que anula o ignora cualquier referencia a la identidad palestina. Marcelo

\footnotetext{
12 Israel se basa en una ley otomana de 1858 que considera todo terreno como estatal, a menos que se pruebe lo contrario. Así, si un terreno es "abandonado" o no es cultivado por tres años sucesivos, se convierte automáticamente en terreno estatal.
} 
Otero (2017: 57), citando a Porto Goncalves, asume que la construcción del ser, no puede estar disociada del estar, es decir, toda sociedad construye su propia forma de vida en el espacio que ocupa haciéndolo suyo. En otras palabras, la apropiación del espacio geográfico genera identidades; la sociedad se territorializa, y el espacio se analiza en la suma de las relaciones políticas, culturales y económicas de las personas. Así pues, la constante destrucción de los olivos significa la destrucción real e imaginaria de Palestina y los palestinos, no sólo como entidades físicas, sino como las manifestaciones imaginadas de dicha realidad (Hamdi, 2017: 15). No es pues sólo una lucha que busca suprimir el sustento económico y territorial del dominado, sino también eliminar una encarnación mayor de la presencia histórica y lazos territoriales de los palestinos con su patria, es decir, la destrucción de un símbolo nacional.

Del lado palestino, los olivos son un símbolo más del sumud o resistencia no violenta. Sin requerir excesivo cuidado, al olivo le toma unos 40 años alcanzar su altura máxima y varias décadas para comenzar a dar frutos; llegan a vivir unos 400 años, aunque algunos han sobrevivido hasta 700 o mil años (Hanley, 2010). Heredados de generación en generación, para los palestinos es un símbolo de su propio arraigo a su patria, de su resolución de permanecer en ella. Los frutos del olivo permiten la supervivencia de muchas familias y hasta hace poco el periodo de recolección de las aceitunas se consideraba un momento festivo para las familias involucradas en el proceso (Mitnick, 2010). Incluso para aquellas cuya economía no dependía de las aceitunas, familias asentadas ya en zonas urbanas, la cosecha ha sido una tradición que reflejaba la historia, unidad y solidaridad familiar (Jabr, 2001). La importancia del olivo en la narrativa identitaria palestina se refleja en las historias individuales, en la literatura, y especialmente en la "poesía de la resistencia"13, donde se describe este árbol como la memoria viva de los pueblos y villas palestinos, testigos silenciosos del sufrimiento de la ocupación. Incluso para aquellos palestinos en el exilio, el olivo se constituye en un lazo de unión física y simbólica con la tierra perdida. Física porque con la creación del Estado de Israel se demolieron innumerables viviendas y aldeas palestinas, pero mucha de la vegetación, incluyendo los árboles de olivo, sobrevivió y se convirtió en referencia geográfica de la antigua propiedad familiar para muchos refugiados y sus descendientes (Braverman, 2009: 244-246). Simbólica al trascender el ámbito de la ocupación y conformar su propio espacio literario y académico en el exilio que encuentra el dicho árbol la encarnación de la cultura palestina ${ }^{14}$.

En la lucha político-identitaria, el papel de algunos colonos israelíes ha sido crucial. El triunfo militar de 1967 fue interpretado por una parte del sionismo más religioso como señal divina favorable a la conquista y ocupación del Gran Israel bíblico ${ }^{15}$. El

\footnotetext{
${ }^{13}$ Braverman señala a poetas como As'ad al-As'ad, Mahmoud Awad Abbas, Tawfiq Zayyad, y el poeta palestino por excelencia, Mahmoud Darwish.

14 En 2017, se inicia la publicación electrónica de la revista en castellano Al Zeytun. Revista iberoamericana de investigación, análisis y cultura palestina. Ver http://alzeytun.org/

${ }^{15}$ Según el libro del Génesis, Dios promete al pueblo judío un territorio mucho mayor a las actuales fronteras territoriales israelíes. «Yo les daré a tus descendientes la tierra que va desde el río de Egipto
} 


\section{Raíces. El olivo en la lucha identitaria entre Israel y Palestina}

nacionalismo israelí, basado en el nacionalismo europeo, es decir secular, fue adquiriendo desde entonces tintes religiosos cada vez más ortodoxos y fundamentalistas en ciertos sectores, aunque minoritarios, de la sociedad israelí y en comunidades judías de todo el mundo. Conforme a esta lectura, los palestinos debían ser expulsados de la tierra de Israel (Pfoh, 16), y una forma de presionarlos es a través de la destrucción de sus medios de subsistencia y símbolos de su pertenencia a la tierra. La narrativa sionista describe las características del árbol (robustez y durabilidad) como indicadores de la naturaleza improductiva de los palestinos que lo cultivan, y, sobre todo, como ejemplo de la incapacidad de los palestinos para embarcarse en formas más modernas de cultivo (Braverman, 2009: 243), es decir, para confirmar el estereotipo del árabe vago frente al espíritu emprendedor del europeo que "hace florecer el desierto". No obstante, se debe destacar que no todos los colonos fundamentalistas aprueban la destrucción de los olivos, dado el carácter sagrado de esos árboles en la tradición judía (Braverman, 2009: 252)

Las acciones violentas emprendidas por los colonos contra los palestinos son cotidianas en Cisjordania, y van desde el incendio de mezquitas, quema de ejemplares del Corán o alfombrillas para el rezo, hasta disparos a paneles solares (Hanley, 2010), el bloqueo de carreteras, lanzamiento de piedras a autos y viviendas, ataques contra villas y tierras agrícolas, incendio de autos, ataques y agresiones contra personas, el envenenamiento, incendio o corte de árboles, especialmente olivos, y daño o robo de cosechas (B'TSELEM, 2017b). Pese a las denuncias de estos ataques, aproximadamente el $85 \%$ de las investigaciones de estos casos terminan sin que se tome ninguna acción y que sólo un 1,9\% de las quejas ante la policía hechas por palestinos terminen con la condena de un civil israelí (Idem). La consecuencia de esta falta de seguridad jurídica es que desde 2014, se hayan intensificado los ataques de colonos, especialmente los ataques contra los olivos, cuya intención es eliminar la presencia palestina del Área C, controlada por Israel (Hammad 2019).

La falta de compromiso político para detener las agresiones de los colonos por parte de las FDI se evidenció cuando éstas prohibieron a los agricultores palestinos ir a sus huertos cercanos a algún asentamiento, en vez de protegerlos de la violencia de aquellos. En 2004, los líderes de cinco comunidades palestinas pidieron a la Suprema Corte de Justicia (SCJ) de Israel que obligara a los militares permitirles acceder a sus cultivos y protegerlos de los ataques de los colonos. La SCJ aceptó la petición y, como resultado, se creó un "sistema de coordinación" que permitiría a los palestinos acceder a sus tierras por varios días dos veces al año: durante las

hasta el río Éufrates. Es la tierra donde ahora viven los quenitas, los quenizitas, los cadmoneos, los hititas, los ferezeos, los refaítas, los amorreos, los cananeos, los gergeseos y los jebuseos» (Génesis, 15:18-21). Justificado en estos versículos, el sionismo más religioso busca expandir la soberanía israelí cuanto sea posible a costa de los palestinos y demás estados árabes vecinos. 
temporadas de arado y la cosecha (B'TSELEM, 2017b) ${ }^{16}$. No obstante, la solución ha sido poco eficaz en cuanto a la falta de coordinación entre FDI y propietarios, y porque deja los cultivos el resto del año a expensas de los colonos, que lo aprovechan para arrancar los árboles o cosecharlos ellos mismos (Hanley, 2010). Lo anterior tiene consecuencias no sólo en la economía sino también en el ánimo de los palestinos, para quienes la tierra es parte de su identidad y las estaciones y la cosecha parte de su mundo cultural (Braverman, 2009:244).

La creciente violencia de los colonos ha dejado su impronta a nivel individual y colectivo entre la población de Cisjordania que vive intimidada por ellos. Aquella que vive cerca de los asentamientos evita acercase o cruzan las áreas cercanas a ellos para llegar a sus cultivos sólo acompañados por militares u otros civiles israelíes (principalmente activistas de Derechos Humanos), algunos otros han abandonado sus tierras por temor a perder la vida (B'TSELEM, 11 nov 2017). Los colonos entienden que la destrucción de los olivares y el hurto de sus frutos no sólo daña de manera individual al dueño del huerto, sino que levantan la ira y frustración en toda la población (Mitnick, 2010), lo que incide en cualquier intento de buscar una salida política al conflicto israelí-palestino que pudiera romper con las aspiraciones maximalistas de los colonos de construir el Gran Israel. Para ellos, el objetivo no son los árboles, sino la tierra, que se pelea palmo a palmo.

Paradójicamente, todos los actos del gobierno y algunos colonos israelíes para destruir, negar y sabotear el acceso de los palestinos a sus olivares han tenido el efecto de conferir al árbol del olivo un enorme poder simbólico del nacionalismo palestino y sobre todo, de la resistencia palestina a la ocupación (Braverman, 2009: 238). De hecho, para contrarrestar la pérdida de los árboles quemados, arrancados, cortados o envenenados, los palestinos realizan regularmente campañas de reforestación en tierras bajo amenaza de confiscación (Hammad, 2019), y emprenden la recolección de las aceitunas de la mano de organizaciones no gubernamentales palestinas como To Be There, israelíes e internacionales tales como B'TSELEM, Stop The Wall, East Jerusalem YMCA (Stop the Wall, 2015), o la británica Zaytoun, de voluntarios de todo el mundo y de la UNRWA, la agencia de Naciones Unidas que desde 1950 da auxilio a los refugiados palestinos en todo Oriente Medio (UNRWA, 2016; 2018). Algunos medios han llamado la Intifada Verde a este esfuerzo colectivo que en los primeros años de la segunda intifada ha permitido sembrar más de 70.000 nuevos olivos en centenares de parcelas (Van Hollen, 2012), además de mantener o recuperar otros cultivos de los territorios (Klochendler, 2013). El objetivo no es sólo económico sino político: la participación de agentes externos al conflicto permite la difusión del problema y, en ocasiones, que los colonos y FDI refrenen sus acciones contra los palestinos.

\footnotetext{
${ }^{16}$ Según datos de Naciones Unidas de 2011, sólo 44 de los 66 checkpoints del Muro de Separación se abren en la temporada de cosecha, entre octubre y noviembre. El mismo informe indica que cerca del $40 \%$ de las solicitudes de "permisos de visitante" para acceder a los campos de olivos que se encuentran detrás del Muro fueron rechazadas. Ver United Nations Office for the Coordination of Humanitarian Affairs, Olive Harvest Factsheet, octubre 2011, https://unispal.un.org/pdfs/OCHA OliveHarvest.pdf
} 


\section{Raíces. El olivo en la lucha identitaria entre Israel y Palestina}

\section{Conclusiones}

Desde 1967, la ocupación israelí de Gaza y Cisjordania permeó en la evolución de la identidad palestina de sus habitantes, que se diferenció en forma y estrategia, de la emprendida por los palestinos en el exilio. En estos territorios, la narrativa identitaria se basaría desde entonces en los vínculos con la tierra y con el firme propósito de permanecer en ella a pesar de la ocupación militar. La lucha se desarrollaría principalmente a través de una resistencia pacífica o sumud ante los intentos de desposesión y expulsión, que los palestinos reivindicarían desde diferentes ámbitos, desde el cultural hasta el geográfico, la pertenencia y lazos del territorio con el pueblo palestino.

La carga económica, familiar, cultural e incluso emocional del árbol del olivo lo ha convertido en un arma en la lucha de la construcción identitaria de los palestinos y, sin desearlo, dicha carga ha sido reforzada tanto por Tel Aviv como por los colonos de los asentamientos en sus empeños de expropiación y destrucción de dicho cultivo.

La recolección de los frutos del olivo ha dejado de ser exclusivamente una celebración familiar para convertirse en un acto reivindicativo de perseverancia y reafirmación identitaria de toda la comunidad palestina, que sin desearlo, ha convertido los campos de cultivo en campos de batalla identitaria y nacional.

\section{Bibliografía}

Abu Quevedo, J. (2002). La cuestión palestina: identidad nacional y acción colectiva (Tesis Doctoral inédita), Universidad Complutense, Madrid http://eprints.ucm.es/4055/

Barreñada, I. (2003). La memoria palestina de la Nakba. Memoria, identidad colectiva y resolución del conflicto, Historia y Política, 10, 273-280.

Braverman, I. (2009). Uprooting Identities: The Regulation of Olive Trees in the Occupied West Bank. Political and Legal Anthropology Review, 32 (3), 237-264

B'TSELEM (2017a). Settlements. Recuperado de https://www.btselem.org/settlements

B'TSELEM (2017b). Settler Violence: Absence of Law Enforcement Recuperado de https://www.btselem.org/settler violence 


\section{Julieta Espín Ocampo}

Hamdi, T. (2017). Edward Said, Postcolonialism and Palestine's Contested Spaces, Journal of Holy Land and Palestine Studies 16 (1), 7-25. DOI: 10.3366/hlps.2017.0150

Hammad, S. (2019). 'A great massacre': Settlers target Palestinian olive trees in uptick of violence. Middle East Eye.

Hanley, D.C. (2010) Israeli Settlers Poison Olive Trees and Torch Mosques in the Wild West Bank, Washington Report on Middle East Affairs, 29 (9)

Hanley, D.C.(2015). Natural History Under Siege, Washington Report on Middle East Affairs, 349 (3)

Hass, A. How the Israeli Army Takes Palestinian Land and Hands It to Settlers. Haaretz, 12/03/2019. Recuperado de https://www.haaretz.com/israelnews/.premium-how-palestinian-land-goes-from-the-army-to-the-settlers$\underline{1.7004514}$

Jabr, S. y Mayfiel, B. (2001) One Palestinian's Story: Grandfather's Olive Groves. Washington Report on Middle East Affairs, 20 (1)

Joint Advocacy Iniciative (2018) The East Jerusalem YMCA YMCA of Palestine Olive Picking Program Recuperado de http://www.jai-pal.org/en/campaigns/olive-treecampaign/olive-picking-program

Kershner, I. In West Bank, Symbol of Peace Now Signifies Struggle. The New York Times, 13/10/2010, p. 6.

Klochendler, P. (2013). "Intifada verde" se apodera de aldea palestina Inter Press Service. Recuperado de http://www.ipsnoticias.net/2013/11/intifada-verde-seapodera-de-aldea-palestina/

Llopis, E. (s/f) Resistencias agrarias y lucha por la tierra en Palestina. Recuperado de https://cerai.org/resistencias-agrarias-y-lucha-por-la-tierra-en-palestina/

Lynfield, B. (2000) Another casualty of war: trees. Christian Science Monitor, 93 (11), 1.

Martinelli, M.A. (2016) La construcción de la identidad nacional palestina. Páginas, 8 (18), 25-48.

Miftah (2017). Olive Trees. More Than Just a Tree in Palestine. Recuperado de http://www.miftah.org/Display.cfm?DocId=25491\&CategoryId=4

Mitnick, J. (2010) Israeli-Palestinian clashes over olive groves feed distrust. Christian Science Monitor. 


\section{Raíces. El olivo en la lucha identitaria entre Israel y Palestina}

Organización de las Naciones Unidas para la Alimentación y la Agricultura (2017). Evaluation of FAO's Programme in West Bank and Gaza Strip 2011-2015. Recuperado de http://www.fao.org/3/a-bd698e.pdf

Otero, M. (2017). La construcción de las identidades palestina e israelí en torno a los conflictos territoriales: un abordaje desde teorías latinoamericanas. Al Zeytun Revista iberoamericana de investigación, análisis y cultura palestina, 1, 56-61.

Oxfam (2010). The Road to Olive Farming Challenges to developing the economy of olive oil in the West Bank. Recuperado de: https://oi-files-d8-prod.s3.eu-west2.amazonaws.com/s3fs-public/file attachments/the-road-to-olivefarming 0 3.pdf

Patel, Y. (2019) Burning trees and beating farmers: Israeli settlers wreak have on another olive harvest Mondoweiss, Recuperado de https://mondoweiss.net/2019/10/burning-trees-and-beating-farmers-israelisettlers-wreak-havoc-on-another-olive-harvest/

Pfoh, E. (2016). El pasado de Palestina en disputa: Arqueología y religión en el conflicto palestino-israelí. Páginas, 8 (18), 10-24.

Rijke, A. y Van Teeffelen, T. (2014). To Exist is to Resist: Sumud, Heroism and the Everyday. Jerusalem Quarterly, 59, 86-99.

Rovira, L., Dell'Aquila, V. y Seminara, L. (2016). Palestina: Historizar el conflicto, pensar el presente, Páginas, 8 (18), 3-9.

Sarafa, R. (2004). Roots of Conflict. Felling Palestine's Olive Trees. Harvard International Review, 13.

Sayigh, R. (1977). Sources of Palestinian Nationalism. A Study of a Palestinian Camp in Lebanon. Journal of Palestine Studies, 6(4), 17-40.

Stop the Wall (2015). Olive Harvest program 2015 - Call for volunteers. Recuperado de https://www.stopthewall.org/2015/09/14/olive-harvest-program-2015-callvolunteers

Organización de las Naciones Unidas (s/f), Refugee Stories Roots of the Soul: The Olive Harvest in Biddu. Recuperado de https://www.un.org/unispal/document/auto-insert-199175/

Talavera, P. (1999). El valor de la identidad nacional. Cuadernos electrónicos de filosofía del derecho, 2, Consultado el 04/05/09. Disponible en: http://www.uv.es/CEFD/2/Talavera.html 
United Nations Office for the Coordination of Humanitarian Affairs (2018). Infestation expected to affect olive harvest in the West Bank The Monthly Humanitarian Bulletin. Recuperado de https://www.ochaopt.org/content/infestation-expected-affect-olive-harvest-west$\underline{\text { bank }}$

United Nations Office for the Coordination of Humanitarian Affairs (2011). Olive Harvest Factsheet, Recuperado de https://unispal.un.org/pdfs/OCHA OliveHarvest.pdf

UN News (2016). New UN report finds that without obstacles Occupied Palestinian Territory's economy could easily double gross domestic product. Recuperado de https://news.un.org/en/story/2016/09/538382-new-un-report-finds-withoutobstacles-occupied-palestinian-territorys-economy

United Nations Office for the Coordination of Humanitarian Affairs (2015). West Bank: Largest Number of trees recorded vandalized by Israeli settlers in a single incident since 2005, The Monthly Humanitarian Bulletin, Recuperado de https://www.ochaopt.org/content/west-bank-largest-number-trees-recordedvandalized-israeli-settlers-single-incident-2005

UNRWA (2018). UNRWA Stands With Farmers From Beit Surik During Olive Harvest Season. Recuperado de https://www.unrwa.org/newsroom/pressreleases/unrwa-stands-farmers-beit-surik-during-olive-harvest-season

UNRWA (2016). UNRWA Supports Palestine Refugee Farmers During Olive Harvest. Recuperado de https://www.unrwa.org/newsroom/press-releases/unrwasupports-palestine-refugee-farmers-during-olive-harvest

Van Hollen, Ana (29, feb, 2012) The West Bank's Green Intifada, Pullitzer Center. Recuperado de https://pulitzercenter.org/reporting/west-banks-green-intifada

Recibido: $18 / 12 / 2019$

Evaluado: $14 / 02 / 2020$

Versión Final: 20/03/2020 